\title{
Cultural Shock in Anita Desai's Novels
}

Sami-Ullah Bhat

Research Scholar

Faculty of Arts and Humanities

Career Point University

Kota, Anantnag, Jammu and Kashmir, India

sami99064.ss73@gmail.com

Dr. Tushar Nair

Career Point University

Kota, Anantnag, Jammu and Kashmir, India

Abstract

Cultural Shock is a phenomenon which is generally experienced by the migrants whether they migrate for jobs, studies or in case of women, after marriage. Anita Desai has dealt with Cultural Shock in her novels along with other major themes.

Anita Desai is one of the pioneers of Indian English Literature. Her novels are replete with themes of Cultural hybridity, alienation, nostalgia cross-cultural clashes etc. These themes are studied under the gamut of theme of Cultural Shock which forms a prominent theme of Desai's novels. The characters she potrays in her novels undergo a transition from one culture to another wherein they receive this Cultural Shock because the new culture appears to them completely alien and contradictory to their opionions. Critics have often praised her for her lucid writing style and fecundity of thought in various books, edited volumes and research articles. However, the theme of Cultural Shock explicitly expressed in 
her novels has not caught the attention of many critics. There seems to be a considerable dearth of critcal appraisal with regard to the experience of Cultural Shock by her characters once they migrate from homelands to abroad.

The present study aims to fill this void by emphasizing and critically examining the novels of Anita Desai with respect to the theme of Cultural Shock. The Cultural Shock of individuals which Anita Desai has potrayed in her books once they migrate from subcontinent towards the western world. The characters make a conscious choice or sometimes a forced decisions to migrate in expectation of better future and life in the new found worlds. The paper analyses the experience of Cultural Shock by these migrants once they reach and confront the alien cultures.

The paper will also deal with the resultant themes of alienation, depression, nostalgia and agony experienced by the characters once they migrate from eastern cultures to western culture. The research article also delves deep into the cross-cultural connections and hybridity produced once the two culture meet and mingle in an individual's personal life.

Keywords-:Drunkard, Hunger for freedom, Man and Women relationship, Alienation, Dream and imagination.

Introduction-:

Cultural Shock is a psychological malady that has afflicted man in varying degrees from time immemorial. It occurs when a person suddenly finds himself transplanted abroad. It has its origin in the anxiety that results from the person's loss of the familiar signs and symbols of his basic culture. The signs or symbols are the thousand and one ways in which each person learns to adjust himself to the many basic situations of daily life when to remove his hat, when to shake hands, when to give tips, how to make purchases, when to accept an 
invitation, when to speak, and when to take statements seriously or not. The cues which may be words, facial expressions or gestures are acquired by each person in the process of growing up and are thoroughly ingrained as the language spoken or the beliefs held by him. Each person's peace of mind, emotional balance and efficiency depends on hundreds of such cues, most of which the person is totally aware. When the newcomer enters the new overseas environment all or most of his learned cues are removed. No matter how full of good will or broad-mindedness he may be a series of props are knocked out from under him making him feel like the proverbial fish "Out of Water".

\section{Stages of Cultural Shock-:}

Cultural shock can be divided in different stages .First comes the rejection of the new country by verbal epithets and criticisms, "The customs are bad" or "The people are bad" or "The climate of this country is very humid". Then comes regression in the form of fantasies and benign mental images of the person's previous culture. All things from the past are suddenly inflated and viewed as being wonderful. All of the newcomer's serious and past misfortunes and problems are forgotten. All of the good things are suddenly remembered. The newcomer may then start to experience some of the symptoms of cultural shock. They may be: Excessive Washing of the hands, Continuous concern over the purity of the drinking water, Concern over the food to be eaten, Fear of physical contact or touching the hired help, Great and often times inappropriate anger over slight delays and minor frustrations, Refusal to learn the new language, Preoccupation with the fear of being cheated, robbed, or molested, Concern over bodily functions, minor pains, and skin eruptions, and The terrible longing to be back home, to be able to have a good cup of coffee and a piece of apple pie, to be able to walk into the corner drugstore and order a chocolate malt, to visit one's relatives, and in general to be able to talk again with people "Who really make sense". 
Reactions against Cultural Shock-:

Individuals differ greatly to the degree in which they are affected by Cultural shock. There are those who cannot live in a foreign country. These are the individuals who become quickly and profoundly traumatized in the new environment. A quick return to the previous environment is the only solution. Then there are those individuals who never have to cope with the real conditions of life in the new country. They stay in the large hotels, responding in fascination to all that is new, and they associate and deal with foreign nationals who can speak their language fluently and who are polite and gracious to all new visitors. Such a Honeymoon stage may last from a few days or weeks to months depending on circumstances. If one is an "important" person he or she will be taken to show places, will be wined and dined, and pampered, and will, upon returning home, speak glowingly about the politeness, the progress, the good will and the friendliness of the country and its people. They may talk at length about the pleasant and superficial experience abroad.

The individual who remains in the new country, however, and who has to learn to cope with the actual conditions of life reacts much differently. He quickly becomes beset with language problems, and most of all, with the fact that the people in the host country appear to be largely indifferent. The newcomer may then proceed to criticize the new country, its ways and its people. The criticism, however, is not valid or objective one. It does not represent an honest and accurate analysis of the actual conditions and the historical events which have created them. The people of the host country might then be perceived by the new comer as stereotypes, usually caricatures of a negative or derogatory type. If the new comer succeeds in learning some of the language and can begin to get around by himself and relate to some degree to the new nationals he may find his way into the new cultural environment. Also, if there is a fellow-countryman who may be worse off, helping him can provide the confidence needed to improve the ability to speak and to get around. 
If the newcomer is able to accept the different and varied customs of the new country as just another way of living he may begin to respond without experiencing the former anxiety, although there may be the moments of strain, at times. Only with a good grasp of all or most of the new customs will this stain disappear. With a good adjustment comes the acceptance of the foods, habits, he may take many things back with him, and will generally speak favorably of the country and its people to whom he has become accustomed.

In some instances however, what might appear on the surface to be good adjustment may actually be fair or marginal adjustment. The newcomer might begin to deny either consciously or unconsciously the fact that he is in a completely new environment and might suppress and repress his true feelings of discomfiture and anger at the many new frustrations. The individual might, for example, be depressed without being aware of it and might superficially appear to be interested and active in the new culture in terms of reaction formation or a "flight into activity". When the prospect of returning home looms large and the time draws closer it may be accompanied by a reduction or loss of interest in the new interests and an automatic "uplifting of Sprits" may occur. The individual may then begin to talk enthusiastically about having reached "the halfway mark" or entering "the downhill portion" of his tour overseas.

At times, it appears that even those persons who are considered to be well adjusted might, if the stress and frustrations continue over a long period, exhibit signs of malaise, disinterestedness and listlessness which has been coined by some observers as "rice-paddy depression", a malady which seems to occur more often in wives than in husbands. The depression is usually dispelled by a move into government quarters or government approved housing where the physical facilities such as lighting, heating and the cultural cues are adequate and also familiar to the individual. A sense of relief and release usually accompanies the change and the family members become more energetic once more, 
especially the wife. This phenomenon appears to be quite prevalent and does not necessarily reflect any basic emotional inadequacy or psychopathology in the individual, for recovery is almost immediate and complete.

\section{Cultural Shock is Costly-:}

The impact of Cultural Shock on the lives of people and their families involves a number of aspects. Experience has shown that Cultural Shock acts in many cases as a stimulus or vehicle to marital discord, excessive drinking and numerous hypochondriacal concerns. It also precipitates excessive sick-call visits to health care centers. This in turn results in financial problems for the people and their families in terms of moving expenses, cost of medicines and the requisitioning of a replacement.

It should also be pointed out that many difficulties that the newcomer experiences are real. A person coming to a tropical area from a temperate zone may suffer from the change of climate, skin irritations and intestinal disturbances. Strange foods and various tropical parasites can upset him. Local standards of health may be different. Another important point is the attitude of the local populace toward the individual who is experiencing cultural shock. If the individual is frustrated and angry towards them, they will sense the hostility. Anger begets anger and hostility begets hostility. One of the difficulties with cultural shock is that it has never been studied carefully and objectively. There is no compendium of information or statistics on the subject. There are no systematic rules to follow. Each person must therefore learn to make his own adjustments, and until he makes them, he is not able to fully play on the job or as a productive and useful member of his community. 


\section{Overcoming Cultural Shock-:}

In order to overcome cultural shock the new comer must realize that each person lives in a unique cultural environment consisting of man-made physical objects, social institutions, customs, ideas, and beliefs. Each person is not born with culture but rather with a capacity to learn it and use it. There is nothing which dictates that a child should learn and eventually speak French, German, Japanese, or Hottentots, nor that he should eat with a fork in his left hand rather than his right hand, or user of chopsticks. All of these things the child has to learn from his parents and the culture as both the best and the only way in which to do things. $\mathrm{He}$ carries this unconscious training and conditioning wherever he goes. When a culture and its ideas, beliefs, values, and customs are well-ingrained it is not an easy matter to acquaint oneself and adjust to the culture of another country. Successful adjustment seems to require the realization that each culture has to be perceived objectively. The solution lies in getting to know the people and their customs, their ways of thinking, and their ways of doing things and the philosophy behind them. Once the person can learn something of the new language and learn to communicate he will gain confidence. A whole new world of cultural meaning open up for him. He may then begin to find out what their interests are. These interests which are usually basic and habitual are almost always talked about and discussed in conversation and can serve as a vehicle or as a basic point for acceptance into the new culture. In addition, it may often be helpful for the newcomer to become an observer or a passive participant at local activities, whether it is a carnival, a religious rite, a "bean-throwing" ceremony or a "bonodori" dance.

The newcomer also has to remember that it is he who is the foreigner and can be expected to be treated as such. He should view his participation as a form of "role playing", realizing that the understanding of the ways of the people are essential, but that he does not have to give up his own basic patterns of thinking, his values, and his beliefs. Through the 
course of time the newcomer learns to make the necessary adjustments to the new country. He learns to shift his perception of himself and the environment and he learns to accept the things that he cannot change.

Given a sufficient degree of open-mindedness, a willingness to learn about oneself and others, and time, the great healer, each individual has the potential for his own recovery from the malady of cultural shock.

Shock Elements in Anita Desai's Novels-:

In the Village by Sea (1982). Anita Desai depicts how Hari becomes afraid by the words of beggar (coconut seller) at Huge-Black Horse. He had not come to the city to be a beggar, crock or murderer. He really did not know what he had come to Bombay for. Now he was in Bombay at last he would find out what future held for him. Even the empty pedestal began to bode evil. Fear gave him the courage to explore further areas near the Black Horse. He first saw a park nearby and thought of spending sometime there. But changed his mind and moved further. He found a long stretch of road bordering the sea. The road was very busy selling their things to the thronging visitors. Suddenly Hari remembered that he had the address of the De-Silva's in Bombay with him and asked the Stallman to guide him to the address. After jeering at Hari in a typical city man's way he directed Hari to Malabar Hills to look for the person mentioned in the address. By the time he arrived at the building called Sea bird housing the apartment of the De-Silva's. He showed the address slip at the gate to the watchman. The watchman took him up in the electric lift to the tenth floor. There he located the number and banged the door. The uniform servant of the De- Silva's came out and shouted at him for not ringing the bell but banging the door like a fool. On knowing that Hari had come to meet his master, he told him that his master and his family had gone to Thul. The servant of the house dismissed Hari unceremoniously on knowing that he had come to 
seek a job with his master. Hari returned to the main gate tired and hungry without knowing what to do. The watchman HiraLal of seabird building noticed Hari and told him that he would take him to a friend in Gonalia Tank near his house. That friend would provide food for Hari and help him stay with him there. Then Hira Lal gave him a job in a Sri- Krishna eating house whose owner Jagu was friend of Hira Lal. The work was very difficult in the fire lit kitchen of the Sri Krishna Eating house. The eating house worked round the clock as the customers came to it day or night for tea and bread and lentils. Jagu paid Hari a rupee a day. It came to seven rupees a week. Hari thought that he would save all the money to take home to his family. The only thing he had in mind was that he could not leave the eating house and longs for the quite nights of his seaside village. Mr. Panwallah takes to Hari very kindly and offers to teach him the art of mending watches. He teaches him the skill during Hari's leisure hours during afternoon. Hari's longing to return Thul and Mr. Panwallah consoling him that he could go back soon as he had not come far away. Hari want to return to Thul after the coconut day. But Jagu asks him to stay till Diwali Hari complains to Mr. Panwallah that Jagu wants to stay till Diwali but he prefers to go back home.

- Death of Pinto (The dog)-: As Hari came up the path by the creek, he realized something was wrong. He heard the wails of his sisters. They were loud and clear in the still house. So he ran fast thinking that something had happened to his mother. He shouted to Lila and asked her in an agitated voice what had happened. Lila was crying, not loudly like her sisters, but quietly and heartbrokenly. He rushed to her and asked her if anything was wrong with their mother. Lila nodded to indicate that it was not their mother. She pointed to a corner of the hut. Hari went in shaken with anxiety and saw Pinto lying dead. Bela and Kamal rushed to him and wept their faces into his shoulders. Hari asked them what had happened to Pinto. Lila told him that somebody had 
poisoned the dog. He could not think who would poison Pinto. But then Lila told him that it was their drunken neighbor one of the Khanekar who should have done that. It was he who came and threatened the other day that he would kill Pinto.

In Fasting Feasting (1999) Desai says how Uma retrieves a purse she has hidden in the pantry that contains all the money she has it is the time of the afternoon when everyone is taking nap, even the servants. She puts on her sandals and goes out of gate breaking into a run towards the rickshaw crossing. Once there, Uma asks a driver to take her quickly to S.T Mary's school. Once she arrives, she realizes that the nuns are also resting but she dares to disturb Mother Agnes. Mother Agnes happens to be walking down the hallway and Uma throws herself at her, weeping. Uma explains why she has come which mother Agnes already knows as papa has written to her. Mother Agnes tells Uma that girls must also learn how to care for babies and then dismisses her, Uma falls to the floor and begins to foam at the mouth and roll around and roll around. She has to be helped by Sister Teresa and the school nurse.

Mama blames Uma's episode on the nuns and school and she continues to teach Uma how to care for Arun. When Uma's marriage gets cancelled with Goyal family. Uma's unmarried state becomes an obstruction as Uma is the oldest and should be married first. Aruna begins mocking Uma which hurts Uma's feelings. The family begins to treat Uma differently, which frightens Uma. She wonders if this means there are "holes and gaps" in the family's unity. Uma worries that "the fabric of family would not hold". When Mama and Papa finally arrange a successful marriage for Uma her heartbreak at this "unenthusiasm" for her is apparent. It ushers her into her first adult disappointment. Uma is forced to confront the bleak possibility that she is about to be married to someone who will never care about her. The fact that her husband immediately disappears is both confusing and frightening for her because she has no experience or anyone to tell her whether this is normal. Uma's response to 
papa finally arriving to take her home also demonstrates her lack of capacity to handle the drama or tension. Uma disappears into her room and covers her eyes and ears so that she doesn't have to hear. It's unclear whether Uma feels shame, abandonment or embarrassment, but it is yet another disappointing experience that forces her to let go of some of her hopes and dreams. The fact that no one will discuss what she has endured when she arrives back home demonstrates how prominently shame factors into the fabric of their family and culture. Although the failed marriage is not Uma's fault yet she is blamed for the shame it has brought to the family. It was Papa and Mama who failed to woo the two grooms that tried to marry Uma but Papa and Mama view their failures as tragedies that cost them two dowries, not as upsetting events for Uma have had to endure.

Desai depicts the new world Arun inhabits in stark contrast to the sights, smells and sounds of provincial India where he grew up. The expansiveness and open spaces of America are deeply foreign to Arun as he had no exposure to outside cultural influences during his childhood of endless studying. While India is crowded with people Arun observes how in American households, "There are so many objects, so rarely any people." The houses, nature, and food are different and they alarm him. This is in stark contrast to the intense and dense family structures and traditions used in India. In India everyone knows everyone else's business and relatives drop by often.

For Arun, Mrs. Patton serves a maternal, confidential role as someone who sees and understands him possibly the first time in his life anyone has understood him. Mrs. Patton seems to see something of herself in Arun and so she imparts a fondness towards him and an attempt to understand him. Arun appears not to know what to make of this unlikely connection because it doesn't necessarily make him happier. Mr. Patton by contrast is a reflection of Papa in his need to dominate and dictate the Patton household. At the same time both parents seem disconnected from their daughter Melanie demonstrating how even in 
widely different cultures, misunderstanding between children and parents is common. The more time Arun spends in the Patton's household the more he begins to realize the similarities between his family and this family from another culture. Here Desai highlights the Universal Family Dynamics and relationships and how they can be fraught and full of misunderstanding and resentment. In Mr. Patton Arun finds a mirror reflection of papa, particularly concerning anyone challenging his authority. Even though Mrs. Patton seems to have more independence than Mama it becomes clear that she still lives subject to her husband's whims and demands. Desai also contrasts American and Indian culture. By viewing the families and cultures in contrast, Arun is better able to see the dynamics of his own family and the value in his own culture. Arun realizes that families in America are no better off their shining, gleaming lives because there is still inherent tension inside them. Even amid so much abundance there is a kind of emotional malnourishment.

Desai hints that although Western society is portrayed as progressive and abundant there is a different kind of spiritual pain in places such as America that does not exist in India. The fact that the novel leaves Mrs. Patton investigating spiritual beliefs shows she is seeking a deeper meaning in life, particularly in light of having overlooked her daughter's illness.

In Custody (1984) When Deven meets Nur at his residence. He is shocked to find that the poet, whom he had high regard for and whom he thought highly of, enjoyed the company of the hooligans or lafangas of the bazaar world, and that his second wife, Imtiaz Begum earlier belonged to a brothel. Nur reprimands Deven first of all for disturbing him and having an intention of interviewing an Urdu poet in spite of being a lecturer in Hindi. Nur believes that Urdu died long ago in 1947 and only its ghost exists in India. Deven finds the atmosphere at Nur's house quite disgusting and the nature of his wife nasty and crude. His wife scolds Nur for drinking too much and scolds even visitors for being self centered. Deven 
is disappointed at the Poet's immense pain and suffering, and seems afraid of delving into the world of poetry any more. He thinks that it is better to live in the real world rather than in an imaginary one. After visiting Nur Deven becomes totally disillusioned seeing his lifestyle. Nur is old, surrounded by flatterers, married to a younger scheming wife who wants to use his glory to be famous herself. Deven is totally traumatized. The novel at this juncture also exposes the false beliefs of the people who have a highly romantic attitude towards poetry and language.

After arranging the tape Deven visits Nur's house to fix an appointment for the interview. When he reaches there, he finds Nur's second wife Imtiaz Begum, who has suddenly fallen ill since the night of her birthday celebrations. The poet is not in a position to be taken aside and interviewed in a systematic manner. In any case, he is prohibited to recite any poetry in the house. Once again, Deven is crestfallen due to the failure of his attempt to convince the poet for an informative interview. Deven is invited by Safia Begum the wife of Nur to her room and agrees to smuggle out Nur for the interview. But Safia Begum makes it clear to him that he will have to pay her for this interview. This new demand of money stuns him and his newly stirred up hope of success is ruined.

Deven is again trapped in a new set of miseries when he listens to the recording done by Chiku. After some initial difficulty the tape begins to play disjointed talks. Deven becomes conscious of the failure of his project. Still he sees a ray of hope in Murad's suggestion that he should take the tapes with him to Mirpore. Deven gets further blow when he receives yet another letter from Nur with a bill for five hundred rupees as room rent. The anxious and helpless Deven goes to Murad's office hoping to convince him. Murad's insensitivity and deceit in this hour of need increases Deven's torment. In place of going back to Mirpore Deven walks aimlessly and reaches a park in Delhi. While looking at the dome of 
the "Great Friday Mosque", Deven finds an answer to his question about the significance of poetic art in the image of the dome.

In Fire on the Mountain when Nanda Kaul opens the letter that the postman had brought. She learns that her great grand-daughter Raka is already on her way to Kasuli. Nanda Kaul is both angry and disappointed. Angry because of her daughter Asha's insensitive and uncalled for meddling into others lives, and disappointed at this unwanted intrusion into her own space. At the fag ends of her life, Nanda Kaul wants only peace and solitude; she wants only Carignano and her little space all to herself. But now an intrusion is thrust upon her. Raka's imminent arrival at Carignano upsets her.

When Raka enters inside the Ballroom. The scene inside the Ballroom shocks Raka. She does not find there the kings, queens and rosy court as said by the Ram Lal. There are only madmen and rioters making wild gestures to the band. It is nothing but rampant lunacy to the child's mind. She is shattered. She wants to close her eyes and wish it away as if it was a nightmare. People have dressed up as various animals and are mimicking animal movements while laughing, drinking, singing, and dancing. The child cannot follow this adult game. She is scared. She starts crying and flees the place. The club scene reminds her of her own father coming home drunk from a party and abusing her mother, while she lay paralyzed with fear. Her mother's cry becomes mingled with the jackal's cry in the ravine outside. She runs back to Carignano to her own room, silent, dark, quiet.

Nanda Kaul receives a telephone call cutting through the dusk. It can't be Ila Das, she thinks because Ila Das left a little while ago, then Ram Lal picks up the telephone and tells her that the call is for her. The call is from the police. They have found Nanda Kaul's name and telephone number in Ila Das cloth bag and they want her to come to the police station to identify the dead body of her friend. She has been raped and strangled. On hearing this from Ram Lal, Nanda Kaul is shocked at the news that nothing registers with her. She cannot 
reconcile herself with the tragic end of her friend convinced that it is a lie. Thinking that her life has been a big lie, Nanda Kaul chokes, she twists her head then hangs it down, lets it hang. She is no more.

The novel ends on a symbolic note with Raka setting the forest on fire and the flames leaping over the mountain. She is now the inheritor of Carignano as Nanda Kaul has desired her to be. 


\section{References}

Bhatnagar, M.K and Rajeshwar (2008). The novels of Anita Desai: A critical study. Delhi: Atlantic publishers.

Weinreich P, Saunderson W (Eds) (2003) “Analysing Cultural, Societal Contexts”. London Routledge.

Fire on the Mountain, Critical Study by Shakti Batra: Surjeet publications.

Jeena, Seema (1985) voice and vision of Anita Desai (45-49), New Delhi: Ashish publishing house.

Swakumar, R (2011). Theme of Alienation in Anita Desai's In The Village By The sea. Asian Review of social -sciences (ARSS) vol 22011 pp 32-38.

Bhatnagar, M.K and Rajeshwar, M (2008). The Novels of Anita Desai: A critical study. Delhi: Atlantic Publishers.

Fasting Feasting. Vintage, 2008.

Fire on The Mountain. Random House India, 2013.

In Custody. Random House, 2008.

Bande, Usha. The Novels of Anita Desai. Prestige Books, 1988.

Das, Arindam. Anita Desai: A Critical Study. Omega Publications, 2011.

Tandon, Neeru. Anita Desai’s In Custody: A Critical Appraisal. Atlantic Publishers, 2011.

Desai, Anita. The Village by the Sea. London: Lester, Orpen and Denny, 2002.

Fire on the Mountain - Penguin books pub 1977, republished in 1981. 